\title{
Reforma dos Órgãos Ministeriais do Trabalho e Bem-Estar Social
}

\section{Estanislau Fischlowitz}

A

1eforma administrativa do Govêrno Federal atacada em seu conjunto por feliz iniciativa do D.A.S.P. há mais de cinco anos, (*) processa-se, atualmente, por providências parciais que visam, separadamente, a seus diversos setores, considerados merecedores de particular atenção.

Ora, várias razões ponderáveis parecem justificar a prioridade a ser concedida, na remodelação do mecanismo governamental, à reforma dos órgãos supremos do Poder Executivo, encarregados da política social e trabalhista.

Um dos principais objetivos da revisão da atual estrutura dos Ministérios é, sem dúvida alguma, a redistribuição mais racional de suas atribuições, agrup ando-se as mais estreitamente relacionadas entre si, e separando-se as divergentes, as alhe:as entre si e as incompatíveis.

Pois bem, em nenhum dos serviços públicos da esfera ministerial, distancia-se a situação vigente tanto das condições acima aludidas como na odministração das questões de interêsse social, cuja chefia central está entregue a nada menc's de cinco Ministérios: Trabalho, Indústria e Comércio; Saúde; Educação e Cultura; Justiça e Negócios Interiores, e Agricultura, excetuando-se ainda as funções avulsas, de importância secundária, que cabem aos demais Ministérios.

Daí resulta, fatalmente, a lamentável ausência de planejamento, da política social. Não seria difícil demonstrar que, apesar da enorme expansão do intervencionismo social público, cujo âmbito cresce, com o tempo, cada vez mais, faltam por completo, quaisquer diretrizes firmes e coerentes à política social nacional. Tudo o que existe nesse particular é uma justaposição meramente mecânica das mais variadas realizações isoladas, empíricas, casuais, sem filosofia comum, sem objetivos claramente delineados, e sem suficiente entrosamento funcional.

A proliferação de diversos órgãos paraestatais e semiprivados, de natureza jurídica, administrativa e soc:al mais variada possível, atingiu, ao mesmo tempo, paulatinamente, no setor em aprêço, limites extraordinários. Na

(*) Veja-se o "Documentário" relativo a essa matéria, publicado no vol. $73, \mathrm{n}^{\circ \mathrm{s}} 1$, 2 e 3 desta Revista, out., nov, e dez. de 1956. 
realidade, a sua coordenação quase não existe, ocasionando paralelismos e lacunas nos seus respectivos campos de atuação, igualmente prejudiciais e contraproducentes. A orientação e fiscalização pelo Poder Executivo de tôdas essas entidades, que demonstram uma sobrecarga administrativa elevadíssima e, às vêzes, níveis insuficientes de eficiência operacional, é quase inteiramente fictícia.

Basta assinalar que, enquanto não faltam, em tese, órgãos federais especializados, com podêres de contrôle jurisdicional, administrativo, financeiro e atuarial, que lhes competem em relação à Previdência Social, embora, talvez, efetivamente não aproveitados de modo plenamente satisfatório - não existe um órgão central encarregado das funções análogas no que diz respeito à assistência social e aos serviços sociais, no sentido mais estrito dessa palavra.

Acresce que, no momento, o ponto de gravidade da administração federal responsável pelos serviços públicos atinentes à proteção ao trabalho e às obras de bem-estar social está deslocado fara o Ministério do Trabalho, Indústria e Comércio, com a sua organização conservada intacta há 27 anos, e com alçada excessivamente ampla, de vez que simultâneamente extensiva tanto aos assuntos sociais como a diversos aspectos da política econômica (indústria, comércio, tecnologia, abastecimento popular etc.). A estrutura dêsse Ministério, integrada nos moldes antiquados da organização plurilateral dos Ministérios, com atribuições que simultâneamente englobavam funções econômicas e sociais do Poder estatal, organização essa, como nos propomos demonstrar a seguir, abandonada alhures, constitui um dos pontos mais nevrálgicos da administração federal. A solução administrativa consagrada no esquema do M.T.I.C., contraria de modo flagrante o princípio da organização autônoma e independente dos órgãos supremos da administração social que, com o decorrer do tempo, se firmou como expressão lógica no plano dos serviços públicos do conceito do Estado de Serviços Śociais, no sentido em que definiu o caráter do Estado moderno HAROLD LASKI. Qualquer que fôsse a posição dêsse Ministério frente à doutrina e prática da contemporânea política tutelar trabalhista e social, a sua jurisdição atingiu uma tão grande amplitude, destituída totalmente de quaisquer similares em outros países acompanhada por tal diversificação das suas funções, que, na prática, se oferecem a sua chefia consideráveis dificuldades no atendimento às suas múltiplas e ainda sempre crescentes responsabilidades administrativas.

A necessidade imperiosa e inadiável de reestruturação do mecanismo governamental na parte que diz respeito aos serviços de política social encontra, por outro lado, nova justificativa no cumprimento das novas reformas sociais - como seia, particularmente, a lei orgânica da Previdência Social - cujo lógico corolário no plano administrativo há de cc'nstituir as providências no sentido do aperfeiçoamento racional dos órgãos supremos do Poder Executivo responsáveis pela sua execução. É óbvio que a revisão integral da legislação previdenciária, que abrange a reestruturação de todos seus órgãos, sem exceção alguma, inclusive os de fiscalização contrôle e 
jurisdição no plano ministerial impõe ao Govêrno novos e sumamente delicados deveres a que dificilmente poderá fazer face com a manutenção da atual organização ministerial em que essas atribuições de enorme importância estão incluídas entre inúmeras outras tarefas de um Ministério com a órbita tão gigantesca de atuação.

Qualquer que fôsse a nossa opinião sôbre o valor efetivo das realizações da política social redistributiva que visam, em última análise, à divisão mais justa e eqüitativa da renda nacional, entre o capital e o trabalho e a elevação dos níveis de bem-estar social das classes econômicamente fracas da população, não poderíamos negar a considerável amplitude e profundidade das providências do intervencionismo social, levadas a efeito no Brasil nesses últimos trinta anos. Entretanto, seria errado concluir que os serviços sociais nacionais tenham atingido, desde já, padrões máximos de saturação. Para comprová-1o basta assinalar o desamparo social quase total da população rural. O Serviço Social Rural constitui apenas o primeiro instrumento pioneiro da política social rural que deverá, no futuro, procurar adaptar às necessidades e condições da população dos campos, dedicada às atividades agropecuárias, às reformas sociais sui-generis, sem tentar s:mplesmente incluir os rurais no campo das reformas sociais "urbanas", de índole trabalhista, previdenciária ou assistencial. Independentemente dessa grave e sensível lacuna no âmbito pessoal da legislação trabalhista e social, não se pode passar em silêncio várias outras relacionadas com a sua incompleta e fragmentária orientação por exemplo, no que diz respeito à flagrante deficiência das medidas construtivas de proteção social à família. Nesse último particular continuamos ainda muito atrasados, de vez que a legislação inadequada e rudimentar sôbre o abono familiar às famílias numerosas ou, antes, numerosíssimas, não proporciona amparo suficiente à família nas classes populares de recursos limitados.

Pois bem, na estrutura atua! do Govêrno Federal não existe um órgão ministerial dotado de podêres e atribuições necessários para atacar a tarefa difícil e complexa de revisão, nesses e a:nda vários outros sent:dos, da órbita da política social nacional.

Dificilmente poder-se-á encarar a revisão da atual deficiente organização do Poder Executivo como panacé:a, capaz de sanar por si só, todos os males das realizações brasileiras da política social.

A remodelação integral do conjunto dos seus diversos setores deverá ser subordinada ao objetivo de atingir com os menores ônus impostos à economia nacional ainda fraca e subcapitalizada, os maiores efeitos sociais.

$\mathrm{O}$ que, a rigor, se pode esperar da reforma administrativa aqui pleiteada é a constituição de um ponto de partida inicial, o mais acertado e razoável possível, no plano de organização do Poder Executivo, para as futuras providências racionalizadoras, aplicáveis à própria essência da reforma social brasileira. Seja como fôr, sem a un:dade de comando no grau supremo da hierarquia administrativa, encontrariam obstáculos instransponíveis tôdas as tentativas no sentido de aprimoramento qualitativo dos serviços sociais existentes que tanto ainda deixam a desejar. 


\section{II}

O problema da organização e funcionamento dos serviços nacionais de trabalho e dos correlatos serviços sociais foi recentemente submetido, pela primeira vez, a exame aprofundado, pela 36 . $^{\text {a }}$ Sessão da Conferência Internacional do Trabalho, realizada em Genebra em 1953, (item VII da Agenda) com a participação ativa do autor do presente estudo. Nas observações e conclusões que resultaram dos trabalhos daquele conclave internacional, não procuramos apontar uma solução ideal, definida de modo rígido e inflexível, e aplicável indistintamente às condições de todos os países interessados. Evitamos, de um modo particular, quaisquer sugestões específicas quanto à organização dos Ministérios "Sociais", partindo do pressuposto que as soluções nacionais têm que obedecer às particularidades de cada país.

De acôrdo com as judiciosas observações consubstanciadas na referida resolução

"a organização do serviço de trabalho dependerá da estrutura governamental geral, das dimensões e da geografia do país em questão, da densidade e distribu:ção da sua população e do tipo e grau de seu desenvolvimento econômico e social" (Item 17).

O objetivo dos trabalhos nesse sentido foi muito mais modesto: tirar da análise comparativa das regulamentações atualmente em vigor algumas conclusões çapazes de servir como denominador comum na orientação administrativa da política protetora e assistencial. E apenas com essas ressalvas que temos que interpretar os resultados da Conferência consubstanciados na resolução aprovada com unanimidade pelo Plenário, no dia 24 de junho de 1953.

A Resolução submete ao exame "a Razão de Ser dos Serviços Nacionais de Trabalho" (I), "as Funções dos Mesmos" (II), "os Princípios Genais Relativos ao seu Funcionamento" (III), "os Problemas de Organização e Questões do Pessoal" (IV), "as Relações com o Público" (V), e, enfim, "as Questões Internacionais" (VI).

$\mathrm{Na}$ enumeração das funções do serviço de trabalho menciona as seguintes: a) proteção geral aos trabalhadcres; $b$ ) relações profissionais e condições de emprêgo; c) mão de obra e $d$ ) seguridade social.

Parece-nos oportuno reproduzir a seguir as considerações dedicadas à razão de ser dos serviços de trabalho:

"1. De um modo geral, a existência do serviço nacional de trabalho justifica-se pela necessidade de aplicar as leis e regulamentos nacionais de trabalho, de pôr em aplicação a política governamental no setor de trabalho e de examinar as questões de trabalho em busca da sua solução. Essas tarefas pressupõem a existência de uma organização administrativa especializada que deveria igualmente ajudar na progressiva melhoria das condições de trabalho e na manutenção da plena ocupação e da paz social.

2. De maneira geral, nenhum organismo governamental poderia, na prática, ser encarregado, isoladamente, da responsabilidade por todos os aspectos das questões relacionadas às funções. 
do serviço de trabaiho. E todavia, essencial que, independentemente do exercício das funções administrativas de caráter particular, o serviço de trabalho participe no plano mais elevado da elaboração da política nacional que vise os objetivos ou afete os problemas tais, como sejam as relações profissiona:s, a paz social e outras questões de interêsse geral do serviço de trabalho.

3. No quadro da administração governamental, é, pois, oportuno prever o serviço de trabalho - ou, em sua ausência, de uma unidade administrativa, capaz de se transformar, com o tempo, num serviço de trabalho independente - que deveria gozar na estrutura geral de um estatuto correspondente às suas importantes responsabilidades".

\section{I}

Não nos parece fora de propósito passar em revista as soluções adotadas pelos principais países, quanto à organização dos Ministérios encarregados dos diversos aspectos da administração social :

A - São muito raros os países que ainda conservam a solução dos tempos passados, entregando a administração do trabalho e dos assuntos soc:ais correlatos aos Ministérios encarregados, também, da administração econômica. (p. ex. a Irlanda e a Suíça).

$\mathrm{B}$ - Na grande maioria dos países existem Ministérios de Trabalho, sendo que em alguns são apenas competentes para os assuntos de proteção ao trabalho sensu strictu, em outros, indiretamente, com alçada extensiva, também, laos serviços sociais correlatos.

Os Ministérios do Trabalho existem, por exemplo, nos seguintes países: Alemanha, Canadá, Ceilão, Colômbia, Cuba, Filipinas, Finlândia, Grécia, Indonésia, Irão, Ind:a, Israel, Japão, Turquia, Venezuela e El Salvador.

Parece interessante assinalar que, depois da reforma da administração pública no plano ministerial levada a efeito na Guatemala em 1956, com a ativa co-participação do autor do pressente estudo, não parece mais existir neste hemisfério nenhum país desprovido de um Ministér:o autônomo do Trabalho.

C - Um grupo distinto constituem os países que optaram claramente a favor da fórmula de "Ministério do Trabalho e Previdência Social". Ministérios assim denominados possuem, por exemplo, a Argentina, o Equador, a França, a Itália, a Dinamarca ("Trabalho e Assuntos Sociais"), Portugal ("Corporações e Previdência Social"), a Síria ("Trabalho e Assuntos Sociais"), o Vietnam ("Trabalho e Ação Social"), a Polônia, a Guatemala etc.

D - Vários países constituíram Ministérios que definiram de "Ministérios de Assuntos Sociais", por exemplo, o Egito e a Noruega.

E - Alguns países juntanam à administração da política social a de alguns outros setores afins. Assim, a Birmânia tem o "Ministério do Trabalho e Habitação", a Suécia, o de "Assuntos Sociais, Trabalho e Habitação", a Holanda, o de "Assuntos Sociais e de Saúde Pública", o Paquistão, o de 
"Higiene, Obras Públicas e Trabalho", o Luxemburgo, o de "Trabalho, Segurs Social e Minas" e assim por diante.

F - Alguns países, como a Nova Zelândia, têm Ministérios específicos "de Seguridade Social", ou, como o Reino Unido, o de "Seguro Nacional e Pensões", independentemente das funções de administração do trabalho entregues ao "Ministério do Trabalho e Serviço Nacional" que existe, aliás, com a mesma denominação, também na Austrália.

G - Enfim, vale a pena destacar a crganização um tanto diferente em vigor nos Estados Unidos, onde, ao lado do Ministério do Trabalho, existe - Ministér:o da Saúde, Educação e Bem-Estar.

$\mathrm{H}$ - Como se conclui da exposição acima reproduzida, relativa à organização do Poder Executivo na esfera ministerial, várias são suas formas, dependendo das características individuais, quanto aos rumos da legislação trabalhista e social, sistemas de organização dos serviços administrativos de grau inferior etc. .

O que lhes é comum é :

1) a separação quase universal da administração trabalhista e social dos órgãos centrais encarregados da administração econômica; e

2) a crescente tendência no sentido de assegurar a unidade de comando da política social, que, todavia, assume uma gama ampla de soluções no plano da organização dos respectivos Ministérios.

\section{IV}

A reforma para a qual procuramos chamar a atenção dos meios esclarecidos da opinião pública labrange dois importantes aspectos separados e nitidamente diferentes do problema: um, cuja solução não comporta maiores dúvidas, impondo-se com a validade quase ax:omática, e outros, técnica e administrativamente muito difíceis e controvertidos.

O primeiro relaciona-se com a separação dos assuntos industriais e comerciais da alçada do Ministério encarregado de modo preponderante da administração social. Parecem dispensar-se os naciocínios mais pormenorizados pana comprovar o acêrto da medida acima aludida. As providências em foco não podem ser separadas da constituição do Ministério de Economia, de vez que é nesse sentido que envereda a reforma ministerial da administração econômica (projeto de lei da Câmara n. ${ }^{\circ} 4$ de 1956). A criação dêsse novo órgão do Poder Executivo envolve, porém, por sua vez, tôda uma série de problemas de sua delimitação fronteiriça com os demais órgãos supremos econômicos e financeiros do Govêrno que não nos parece necessário abordar nesta altura em maiores detalhes.

Um outro, objetivamente muito mais complexo conjunto de problemas, passível de mais contraditória apreciação técnica oferece a questão sempre mu.to discutida, tanto no Brasil como no estrangeiro, quanto às respectivas vantagens e defeitos da fórmula "unitária" ou "bipartida" da administração social de grau supremo. De acôrdo com a primeira, tôdas as atribuições nessa matéria caberiam a um só Ministério cuja competência abrangeria 
juntamente as questões de proteção do trabalho e as de amparo social sensu İato, ao passo que a segunda preconiza a bifurcação da administração social em dois Ministérios, um encarregado das providências tutelares, e outro da administração dos institutos sociais assistenciais e previdenciários.

Como podemos observar, consultando a legislação comparada nacional da maioria dos países, não existe, nesse particular, unanimidade, de vez que se notam a respeito as soluções mais contraditórias possíveis, a despeito da tendência, cada vez mais visível, nos países com legislação social evoluída e progressista no sentido da adoção da segunda dessas fórmulas.

Quanto à reforma administrativa brasileıra, parece prevalecer a orientação que preconiza a aprovação da fóímula bipartida, ao nosso modo de ver, como nos propomos justificar a seguir, adaptada de modo melhor às condições objetivas do nosso panorama social.

Com efeito, apenas os Pareceres da Comissão Interpartidária (Item 13) e da Comissão de Reforma Administrativa (Art. 49-52) pronunciaram-se, isoladamente, a favor da solução unitária.

Muito pelo contrário, todos os demais anteprojetos, projetos e pareceres opinativos concedem tôda preferência à constituição dos Ministérios separados de 1) Trabalho e 2) Previdência (ou Previdêncía Social, dos Serviços Sociais, da Ação Social).

De um modo particular, enveredam nesse caminho:

1) O anteprojeto inicial do Govêrno (arts. 37-38 do respectivo diploma legal);

2) o projeto elaborado pelo P.S.P. (arts. 29-30);

3). o parecer da U.D.N. (item 18);

4) o projeto de autoria da Associação Brasileira de Planejamento (organograma $\mathrm{n}^{\circ}$ 18);

5) o projeto de lei n. ${ }^{\circ} 3.563-\mathrm{A} / 1953$ apresentado pelo Poder Executivo (art. 6), e, enfim,

6) as emendas da Comissão de Legislação Social ao projeto de lei da Câmara (n. ${ }^{\circ} 4$ de 1956) que dispõe sôbre a criação do Ministério da Economia (n. 9-C).

Quais são os "prós" e "contras" comumente invocados como justificativa das duas soluções opostas?

É inegável a intima conexão entre ambos os setores em aprêço.

As medidas tutelares e protetoras trabalhistas e as realizações de amparo social são, na realidade, verso e reverso da mesma medalha. Obedecem às mesmas final:dades. Varia apenas a técnica a que recorrem em busca do bem-estar das classes beneficiadas. Ao passo que aquelas primeiras envolvem compromissos legais impostos aos empregadores, essas últimas procuram atingir os objetivos colimados recorrendo às soluções institucionais de responsabilidade coletiva, com bases contributivas, semicontributivas, ou bem diretamente financiadas pelos fundos públicos. O que, por sua vez, comprova a estreita ligação entre êsses dois ramos da política social é o fato de que 
idênticos objetivos específicos podem ser alcançados tanto pela legislação protetora como pela legislação social, securitária ou de orientação congênere.

Basta, para comprová-lo, enumerar alguns casos em que se oferece a escolha entre uma e outra técnica no atendimento às mesmas necessidadies, e que apresentam certa atualidade no panorama brasile:ro.

Assim, por exemplo :

1) a proteção econômica à matern:dade pode ser assegurada, como acontece atualmente, por meio das obrigações patronais relacionadas com a indenização da trabalhadora gestante - ou, bem, como o preconiza o projeto de lei orgânica da Previdência Social, mediante o seguro social aplicável à maternidade;

2) o amparo às vítimas dos riscos profissionais pode assumir a forma de compromissos que oneram direta e indiretamente os empregadores - ou, muito pelo contrário, dentro da Previdência Social, como seguro social contra os riscos de acidente de trabalho e enfermidade profissional;

3) a assistência aos trabalhadores despedidos pode ser garantida tanto através dos institutos trabalhistas de "indenização" e "estabilidade", solução em vigor no momento - ou, então, pelo seguro-desemprêgo, ou seguro-despedida, solução atualmente em cogitação;

4) enfim, a proteção social à família sob a forma de redistribuição do "fundo salarial" em prol dos trabalhadores com maiores encargos de sus-. tento de família pode ser garantida, a rigor, tanto por meio do salário-mínimo "familiar" e outras providências concomitantes - ou pelo abono familiar, pela atuação das caixas de compensação e supercompensação dos compromissos familiares, por meio dos fundos especiais de proteção salarial à família, etc. .

Pois bem, essa exposição, manifestando a interdependência funcional entre os dois grandes instrumentos da política social, acima focalizados, pode ser invocada como poderoso argumento a favor da unidade dos serviços centrais ministeriais encarregađos da sua administração.

Não faltam outros raciocínios capazes de justificar a unificação dos dois setores no grau supremo da hierarquia ministerial. Ambos constituem expressão inequívoca das novas e importantes responsabilidades assumidas pelo Estado social intervencionista. A sua direção não pode deixar de cbedecer à mesma filosofia e tem que demonstrar, em essência, as mesmas atitudes intelectuais, morais e, até, sentimentais, na regulamentação dos problemas genuinamente humanos, pessoais, intimos e, em parte, imponderáveis, de proteção às classes menos favorecidas da sociedade. Tem, pois, que fugir à rigidez das normas legislativas e à inflexibilidade na sua aplicação e interpretação dentro dos específicos processos administrativos de que faz uso. Tanto num como noutro setor o pleno sucesso das providências protetoras depende, em grande escala, da cooperação harmoniosa dos competentes serviços públicos com as classes amparadas e beneficiadas tanto na orientação como na implementação das providências. Enfim a política social pròpriamente dita, protetcra e social, de índole pública tem que ser conjugada com a política social privada, isto é, dentro da primeira, com os entendimentos 
contratuais coletivos entre o capital e o trabalho, e dentro da segunda com diversas medidas assistenciais, voluntárias e facultativas, que completam o intervencionismo estatal.

Jutro importante aspecto do problema relaciona-se com o campo pessoal da uplicação das providências sociais. De início, em certa correlação com os conceitos hoje superados da doutrina marxista, a "clientela" das obras coletivas de bem-estar social estava limitada, do mesmo modo como as normas tutelares ao trabalho, às classes trabalhadoras socialmente dependentes, o que contribuía muito para acentuar sua ligação à proteção ao tnabalho .

Entretanto, com o tempo, as realizações sociais de caráter coletivo distanciam-se, sob êsse ângulo, das soluções adotadas pela legislação trabalhista. O campo pessual de aplicação das reformas sociais ultrapassa cada vez mais o grupo dos trabalhadores assalariados, incluindo-se no seu âmbito os independentes e autônomos, todos os econômicamente ativos, ou, mesmo, tôđa a população nacicnal.

Na economia rural, dada a existência na pirâmide social da agricultura dos numerosos grupos intermediários entre o trabalho assalariado e a exploração das atividades de lavoura por conta própria (meeiros, parceiros, arrendatários, etc.), as reformas sociais rurais têm que beneficiar fatalmente importantes camadas sociais fora do proletariado rural no sentido estrito sócio-jurídico. Não se pode deixar de notar a paulatina evolução no sentido dêsse mais amplo conceito das reformas sociais que se delineia também no Brasil (extensão do campo de operação da Previdência Social, Serviço Social Rural, etc.). Evidentemente, a circunstância ùltimamente salientada pode ser aduzida a favor da separação da administração ministerial, responsável por cada um dos dois grandes setores em foco.

As técnicas de operação dêsses dois setores divergem consideràvelmente, necessitando outras qualidades de seus respectivos órgãos supremos de comando.

Exite, por seu turno, muito maior vinculação entre a previdência social e a assistência social, inclusive os serviços sociais, cio que entre a previdência social e o trabalho.

Por outro lado, as realizações no setor social assumiram no Brasil com o tempo tal amplitude e evidenciam, simultâneamente, tantos defeitos estruturais e funcionais que não nos parece possivel negar as vantagens da criação no mecanismo ministerial do Govêrno de um órgão autônomo, com atribuições linitadas só a êsse setor, sem competência extensiva à administração trabalhista.

Enfim, enquanto a pasta do Trabalho, dada a natureza de suas finalidades e funções, difícilmente pode ficar alheia a vários elementos da política nacional, a administração ministerial social pode e deve afastar-se da influência dêsses critérios, seguindo rumos objetivos, inspirados, dentro do possível, nas considerações de natureza técnica. Basta indicar a notória situação crítica da Previdência Social para comprovar as vantagens que apresentaria a suá futura subordinação a um Ministério de caráter menos político e mais técnico.

Em suma, todos os raciocínios acima expostos parecem de molde a justificar o desdobramento dos órgãos ministeriais "sociais". 
Cutra, igualmente importante e difícil questão, cuja apreciação parece passivel de interpretações contraditórias prende-se à inclusão de alguns aspectos de saúde, sobretudo assistência médico-social terapêtutica, dentro do âmbito de atuação do novo Ministério - ou da sua exclusão como matéria da alçıda privativa do Ministério da Saúde. Na realidade, não se pode negar a estreita correlacão entre um e outro setor, evidenciada pela crescente expansäio das atividades médico-assistenciais da Previdência Social. Basta assinalar que, aliás, sem justificativa muito convincente, a separação dêsse setor do campo das instituições de Aposentadoria e Pensões e a sua transferência para a administração federal da saúde foi preconizada num recente parecer do Conselho Nacional de Economia. Os serviços de medicina terapêutica ocupam, por sua vez, lugar de destaque nas atividades dos Serviços Sociais patronais de indole assistencial (SESI e SESC).

Convém relembrar que dois pareceres, os do P.T.B. e da Comissão Interpartidária, dão ênfase especial à correlação entre os problemas da saúde e assistência social, o primeiro - sugerindo a constituição de um Ministério de Previdência e Saúde e o segundo - preconizando a criação de um Ministério de Saúde e Assistência.

Enitretanto, depois de atenta análise dêsse problema, não se vê bem a necessidade da criação acima dêsses setores: de saúde e de serviços sociais sensu lato de uma cúpula ministerial comum, isto é, de um Ministério de Previdência Social, Assistência Social e Saúde. Os aspectos sanitaristas que perfazem a grande maioria das atividades do Ministério da Saúde não têm a não ser uma ligação remota com as responsabilidades da polít:ca social. Depois da recente e muito acertada separação do Ministério da Saúde do antigo Ministério da Educação e Saúde seria retrocesso recorrer, mais uma vez, às providências capazes de afetar a autonomia dos órgãos centrais de saúde. A chefia do Ministério da Saúde tem que caber fatalmente a um médico. E, à luz da abundante experiência no estrangeiro, não seria, por várias razões ponderáveis, de bom alvitre confiar incondicionalmente a um facultativo a direção das realizações da política social. Se tudo nos leva a crer que apresentaria vantagens manifestas a maior coordenação da administração higiênico-sanitária e social, tal objetivo podería ser alcançado de melhor modo por meio da constituição de uma comissão interministerial dotada de amplas atribuições e incisivos podêres - do que mediante a unificação num só Ministério dos respectivos setores administrativos.

\section{V \\ MINISTÉRIO DA PREVIDÊNCIA E ASSISTÊNCIA SOCIAIS}

Tecendo considerações a propósito da reforma ministerial acima focalizada não se pode deixar de fazer referência a várias tentativas anteriores no sentido da reestruturação unitária de todos os serviços sociais do Brasil, embora atacadas no plano diferente da reorganização da suprema administração federal. A primeira estava ligada à lei orgânica dos Serviços Sociais do Brasil (D.L. n. ${ }^{\circ} 7.526$, de 7 de maio de 1945) na qual se previu a criação do Institutc dos Serviços Sociais do Brasil (I.S.S.B.). A segunda foi a constituição em 1951 pelo Decreto n. ${ }^{\circ} 30.020$, de 29 de setembro de 
1951, da Comissão Nacional de Bem-Estar Social. Ambas não lograram o êxito desejado e tiverąm que ser abandonadas. A primeira, porque não foi considerada oportuna a criação de um organismo paraestatal gigantesco, que reuniria o conjunto dos serviços previdenciários e assistenciais. A segunda porque uma simples Comissão ad hoc, destituda de podêres e atribuições administrativos necessários para o desempenho das suas importantes tarefas, não se revelou suficiente para garantir a un:dade das realizações sociais. Pois bem, o malôgro dessas primeiras tentativas não afeta em nada a razão de ser de um novo esfôrço dessa índole, orientado no sentido da melhor adaptação da organização ministerial às necessidades e exigências administrativas da reforma social no seu conjunto.

Quanto à denominação do Ministério em questão, tem importância relativamente secundária. Başta, a título de exemplo, indicar algumas examinadas no Brasil ou adotadas no estrangeiro: Minstério de Bem-Estar Social, de Administração Social, dos Serviços Sociais, dos Assuntos Sociais, da Previdência e Assistência Sociais, etc. Não nos pareceria contudo convincente a adoção da nomenclatura unilateral que refletiria exclusivamente a inclusão no seu âmbito da Previdência Social, sem qualquer referência aos demais setores.

A providência em aprêço não poderia consistir de modo algum numa simples justaposição dos diversos órgãos tirados da atual alçada de diferentes Ministérios existentes.

Com efeito, as repartições ađminıstrativas não são estruturadas de modo a corresponder à unidade orgânica da assistência social e dos serviços socia:s.

Parece-nos, portanto, indispensável constituir um novo Departamento Nacional de Assistência Social e Serviço Social que abrangeria as atribuições atualmente entregues a tôda uma série de órgãos ministeriais, inclusive as relativas à proteção social à família ("abonos familiares" etc.) .

Quanto a órgãos consultivos, parece necessário criar um novo Conselho da Política Social integrado pelos representantes dos demais Ministérios interessados, pelos porta-vozes das classes sociais oneradas e beneficiadas pelas diversas realizações de política social, assim como pelos técnicos altamente especializados em assuntos sociais. Esse Conselho - órgão de assessoria técnica do novo Ministério - deverá ser subdividido em várias comissões (Previdência Social, Assistência Social, Serviços Sociais).

Alguns órgãos não poderão ser transferidos integralmente sem alterações necessárias para o âmbito do novo Ministério em vista da necessidade da sua divisão em setores que deverão continuar integrados nos Ministérios a que pertencem, e em outros, que passariam à órbita do Ministério ora projetado.

Assim, por exemplo, o Serviço de Estatística de Previdência e Trabalho não poderá ser deslocado "tal qual" para o novo Ministério, de vez que a estatística de trabalho deverá ficar dentro da alçada do Ministério do Trabalho.

Do mesmo modo, o atual Serviço Atuarial deverá ser dividido em dois: o Serviço a ser encarregado da atuária previdenciária, que passará ao Ministér:o em questão, e o Serviço competente para os aspectos atuariais do seguro 
privado, que não poderá ser separado do Ministério em que ficar lotado - Departamento Nacional de Seguros Privados e Capitalização.

O que precede refere-se "mutatis mutandis" também à Comissão Permanente de Direito Social.

A lei que criaria o novo Ministério não poderia deixar de indicar, de início, a definição geral das suas atribuições: como, por exemplo, "a execução da política social do Govêrno federal relativa à melhoria das condições de vida das classes menos favorecidas da população nacional, com o fim de thes garantir níveis desejáveis de bem-estar social".

O texto da respectiva lei deverá, a seguir :

1. Enumerar as principais funções do Ministério;

2. determinar :

a) a sua estrutura;

b) os órgãos que ficarão sob sua jurisdição; e

c) as entidades que serão subordinadas a sua orientação e fiscalização;

3. prever a verba destinada às despesas com a sua organização;

4. constituir a Comissão Organizadora do Ministério, encarregada inclusive da elaboração de seu Regulamento, marcando-se o prazo improrrogável em que deverá apresentar seu relatório ao Poder Executivo.

Sem entrar por enquanto em maiores detalhes quanto ao esquema completo do Ministério projetado, parece oportuno indicar, a seguir, desde já, os órgãos existentes que deverão ser, de qualquer modo, enquadrados na sua órbita.

\section{A - Ministério do Trabalho, Indústria e Comércio}

I - Repartições Administrativas :

1. Departamento Nacional da Previdência Social

2. Serviço de Estatística de Previdência (sem a parte relativa à estatística do trabalho, com a transferéncia das funções relativas ao abono familiar)

3. Serviço Atuarial na parte relativa à atuária previdenciária II - Ôrgãos colegiados :

Conselho Superior da Previdência Social ("Conselho Superior de Recursos da Previdência Social" previsto na !ei orgânica da Previdência Social), Comissão Permanente de Direito Social, na parte relativa à legislação social.

III - Entidades vinculadas ao Ministério:

a) dentro da jurisdição do Ministério:

1. Institutos de Aposentadoria e Pensões e a CAFESP, assim como o IPASE

2. SAPS

3. Fundação da Casa Popular

4. SAMDU 
b) sob a orientação e fiscalização do Ministério:

1. SESI

2. SENAI

3. SESC

4. SENAC

$B-$ Ministério da Aǵricultura

Entidades vinculadas ao Ministério:

1. INIC

2. SSR

C - Ministério da Justiça e Negócios Interiores

Repartições Administrativas :

Serviço de Assistência a Menores

D - Ministério da Saúde

Repartições Administrativas :

Departamento Nacional da Criança

órgãos colegiados :

Conselho Nacional de Alimentação

E - Ministério da Educação e Cultura

Órgãos colegiados :

Conselho Nacional de Serviço Social

Entidades vinculadas ao Ministério :

1. Fundação Cristo Redentor

2. Fundação Darcy Vargas

3. Instituto Benjamin Constant

4. Instituto Nacional de Surdos e Mudos

Do mesmo modo, deveria ser subordinada à orientação e fiscalização do novo Ministério a Legião Brasileira de Assistência.

Enfim, para assegurar o perfeito entrosamento da política social pública e privada, evitando-se a atual dispersão e descoordenação das atividades assistenciais, contraproducente e antieconômica, é imprescindível submeter à orientação e fiscalização do "Ministério Social" tôdas as organizações e entidades privadas, associativas, religiosas, classistas, profissionais e de índole diferente, desde que tenham por objetivo a prestação da assistência e de serviços sociais e, sobretudo quando recebam quaisquer favores diretos ou, mesmo, indiretos dos podêres púbicos cu das organizações paraestatais. (*)

(*) $\mathrm{Na}$ enumeração dos diversos órgãos não prestamos propositadzmente maior atenção a sua acurada conceituação jurídica; a lista dos mesmos pode pois acusar algumas inexatidões que, todavia, não afetam a exposição da suger:da estrutura do Ministério. Não nos foi, também, possível justificar pormenorizadamente a inclusão na sua órbita de alguns órgãos (como seja p.ex. o INIC) ou a exclusão de outros (Caixas Econômicas federais, alguns órgãos vinculados ao Ministério da Guerra etc.) que parecem em tese passíveis de interpretações muito contraditórias. 


\section{I}

\section{MINISTÉRIO DO TRABALHO}

E relativamente muito mais simples o problema da futura organização do Ministério do Trabalho, cujo âmbito de atuação se tornaria muito mais restrito, limitado às funções relacionadas com a sua denominação.

Entretanto, seria errado concluir que na sua reforma deverá ser conservada intacta a estrutura atual, um tanto obsoleta e funcionalmente ineficiente, com a mecânica inclusão na sua alçada dos órgãos remanescentes, uma vez levada a efeito a amputação das demais repartições e entidades, deslocadas para os novos Ministérios : o "social" e o "econômico".

Com efeito, essa oportunidade deverá ser aproveitada para a revisão racional dos órgãos daquele Ministério, subordinada ao propósito de lhes assegurar as condições administrativas mais propícias ao seu funcionamento plenamente proveitoso. Sem pretender abordar em maiores detalhes e esgotar a essa altura tôdas as modificações que se oferecem nessa ordem de idéias, desejamos apontar em seguida apenas algumas cuja justificativa nos parece particularmente convincente.

1. O SEPT deverá de ora em diante concentrar tôda sua atenção sôbre as tarefas relacionadas com a estatística de trabalho pròpriamente dita, tanto como instrumento de esclarecimentu da economia de trabalho - até certo ponto, ainda terra virgem -- assim também como subsídio, de crescente importância, para a implementação dos instrumentos da política nacional salarial (sobretudo o salário mínimo) que, aliás, constitui desde já, um dos setores preferenciais da sua atuação: Muito pelo contrário, independentemente da eventual constituição do Instituto Nacional do Salário, prevista no anteprojeto de lei sôbre o salário móvel, seria de bom alvitre separar das suas atuais atribuições as atinentes às próprias providências de política de salários que deveriam caber a um órgão especializado (veja-se o Item 7).

2. Como já foi acima aludido, as funções do Serviço Atuarial relativas aos seguros privados e à capitalização perderiam a sua razão de ser, caso a administração governamental dêsse setor fôsse transferida ao Ministério da Economia; do mesmo modo essa repartição deveria ser extinta, na parte previdenciária, dada a atribuição ao Ministério "social" dos podêres relacionados à Previdência Social.

3. Uma grave lacuna no âmbito dêsse Ministério constitui a falta de um órgão de planejamento. É a uma Comissão especial, com a estrutura baseada na experiência da Comissão Nacional do Bem-Estar Social, já extinta, e da Comissão de Estudos e Planejamento (na prática, quase inexistente) que deverá caber o desempenho das respectivas tarefas, particularmente vitais e promissoras em face dos rumos acentuadamente variáveis e extraordinàriamente plásticos da legislação de trabalho.

4. O Departamento Nacional do Trabalho continuaria incompleto se não incluísse a Divisão de Mão de Obra que deveria atacar a organização planejada do mercado de trabalho, com atenção especial voltada para a criação e o desenvolvimento dos serviços de colocação do trabalho e para 
o construtivo combate a vários fenômenos de patologia social, tais como c tesemprêgo e o subemprêgo, a rotatividade de empregos etc., que ùltimamente assumiram considerável freqüência e gravidade. A essa inovação atribuímos importância tôda particular, pois o atual desinterêsse pelos problemas agudos e complexos do mercado de trabalho carece de qualquer fundamento objetivo.

5. Em íntima conexão com a providência acima aludida no Item 4, deveriam ser reestruturados os dois úrgãos oficiais (S.M.O.C.T. e S.C.T.) encarregados das funções de bôisa de trabalho, cuja duplicação dentro do mesmo Ministério não se explica de mudo algum, e que, na prática, limitados ao Distrito Federal, ambos subequipados e desaparelhados, não podem corresponde: às suas tarefas de incontestável relevância tanto econômica como social.

6. A reorganização do Serviço de Documentação deverá visar a criação de uma repartição encarregada de estudos e pesquisas, de caráter científico. Por mais incrível que pareça, tal órgão falta por completo. As providências empíricas e meramente intuitivas, destituídas de necessárias bases de pesquisa social, apresentam o grave risco de entrar em flagrante contradição com as condições objetivas do panorama social a que se aplicam e de levar aos efeitos contraproducentes.

7. Como já foi acima salientado, o intervencionismo salarial dos podêres públicos alcançou com o tempo entre nós uma extensão e intensidade que relegam a um lugar secundário tôdas as demais funções da administração do Trabalho. Aos poucos definem-se na teoria os rumos mais salutares e proveitosos da intervenção salarial do Estado que, todavia, ainda não encontraram reflexo na legislação vigente, ainda sempre não desprovida de certos defeitos sob o ângulo social e econômico. É, pois, uma necessidade imperiosa a constituição de uma célula administrativa central, capaz de planejar as respectivas providências, preparar a regulamentação normativa dos respectivos institutos (salário mínimo geral, profissional ou familiar, participação nos lucros, salário móvel etc.) e acompanhar de perto a sua aplicação.

8. O principal vício do Serviço Nacional do Trabalho foi e, até certo ponto, continua sendo a sua excessiva centralização. Muito foi feito nos últimos anos para deslocar seu ponto de gravidade do centro para a periferia. Entretanto, muito ainda resta fazer para aproximar tanto quanto possivel os órgãos do Miristério das principais áreas de concentração das classes trabalhadores urbanos e rurais, reforçando-se simultâneamente os podêres outorgados às Delegacias Regionais do Trabalho.

9. A proteção realmente eficaz ao trabalho pressupõe o funcionamento em condições máximas de eficiência da Inspetoria do Trabalho. A sua reestruturação integral deverá abranger, antes de mais nada, a maior autonomia dêsses serviços e a ampliação de seus podêres, independentemente da rigorosa seleção do pessoal a seu serviço.

10. Uma série de problemas de índole específica relacionam-se com a existência, fora da alçada direta do Ministério, dos órgãos mantidos e administrados pelo Fundo Sindical. Sem poder separar as sugestões relativas 
à sua maior integração na estrutura dos serviços governamentais do trabalho do reexame da orientação das respectivas realizações, que ultrapassaria os quadros dêste trabalho, desejamos, apenas focalizar êsse problema, sem formular, por enquanto, nenhuma sugestão específica nessa delicada matéria.

11. As relações internacionais do Ministério assumiram tal vulto que não pode mais continuar desprovido de um órgão administrativo estável e especializado, encarregado dessas funções sui generis. Isto refere-se de um modo particular à cooperação cada vez mais ampla com a Organização Internacional do Trabalho, cujos estatutos prevêem, aliás, expressamente a possibilidade de con̦tatos diretos entre a Repartição Internacional do Trabalho e os órgãos supremos dos serviços nacionais de trabalho - sem recurso ao mecanismo diplomático comum. O Brasil é um dos últimos grandes países socialmente adiantadios que ainda não fizeram uso dessa faculdade, com os resultados nìtidamente insatisfatórios quanto a sua colaboração com aquêle importante organismo internacional.

12. O problema da inclusão do trabalho rural, exercido dentro da economia agropecuária, no campo de aplicação dos institutos tutelares de trabalho abrange tôda uma série de questões de enorme complexidade técnica. Tudo nos leva a crer que êsse grande objetivo não poderá ser alcançado mediante a simples ampliação à zona rural do âmbito das providências protetoras "urbanas". Nessas condições parece reunir todos os requisitos técnico-administrativos a idéia de distribuir as tarefas da política trabalhista rural a uma repartição especial, possivelmente dentro do arcabouço da organização do Departamento Nacional do Trabalho.

Eis apenas alguns subsídios isolados e incompletos pana a reforma estrutural do Ministério do Trabalho que, concentrando de ora em diante tôdas as suas atividades sôbre os deveres próprios, protetores e tutelares, sem diversão para outros, de natureza alheia a seu campo específico de atuação, e valendo-se da sua nova organização, mais racional e aperfe:çoada, poderá, sem dúvida alguma, atingir padrões superiores de rendimento funcional.

\section{VII}

Não se deve, evidentemente, nutrir esperanças exageradas quanto às vantagens diretas e imediatas da reorganização da administração pública na esfera ministerial. A reforma administrativa ministerial não pode ser considerada como fim em si, mas apenas como ponto de partida para as futuras providências normativas e administrativas relativas ao conjunto de reformas sociais.

Não existem, aliás, quanto à subdivisão dos órgãos centrais do Poder Executivo, conceitos axiomáticos, cientificamente inatacáveis, de validade universal. O que parece constituir o objetivo natural e inconteste dessa reforma é a sua orientação no sentido de juntar, dentro de um Ministério, setores afins e correlatos, funcionalmente interdependentes, evitando-se a sua atual dispersão e a atribuiçâo aos Ministérios atualmente existentes das 
funções mais diversas e disparatadas. Como salientou com muito acêrto a excelente exposição que acompanhou o primeiro anteprojeto de reforma administrativa :

"No que se refere à parte pròpriamente estrutural da administração, o objetivo essencial é assegurar uma distribuição mais harmoniosa das atividades do Estado, agrupando-as pela similitude de seus objetivos, reduzindo a um número razoável os contatos diretos do Presidente da República, simplificando o campo de ação de cada Ministério e assegurando uma coordenação adequada de tôdas as unidades do sistema".

É sob êsse ângulo que a criação do Ministério proposto, acompanhada pelas alterações relativas ao Ministério do Trabalho, parece reunir tôda uma série de evidentes vantagens. Na falta de um estado maior da política social, não se pode sequer pensar em providências bem planejadas da política social, extensivas às suas múltiplas técnicas.

Com certo exagêro pode-se, até, afirmar que a verdadeira política social ainda, na realidade, não existe no Brasil - se fizermos abstração das realizações isoladas, parciais, empíricas e quase totalmente descoordenadas, tôdas elas altamente dispendiosas, com sobrecarga administrativa elevada, e que não sòmente engendram inevitàvelmente prejudiciais lacunas, paralelismos e conflitos jurisdicionais, como também, com freqüência, obedecem à orientação contraditória. Tudo o que existe. no momento, no setor em aprêço parece passível de uma revisão racionalizadora integral.

Ora, acreditamos que a nova estrutura ministerial poderá criar bases oportunas para tal revisão renovadora do conjunto de reforma social brasileira.

Nada mais - mas também nada nenos. 